\title{
Coping With The Risk Of Interest Rate Fluctuations: The Case Of Kuwait Banks
}

\author{
Omar M. Benkato, (E-mail: obenkato@bsu.edu), Ball State University \\ Mahmoud M. Haddad, (E-mail: mhaddad@utm.edu), University of Tennessee-Martin \\ Nabeel Al-Loughani, (E-mail: loughani@cba.edu.kw), Kuwait University \\ Michael N. Baur, (E-mail: mbaur@bsu.edu), Ball State University
}

\begin{abstract}
This study analyzed immunization behavior of a sample of eight Kuwait banks during the 1994 through 2000 period. The financial market in Kuwait experienced relative stability of interest rates during the analysis period. The sample banks seemed to adjust their portfolio of assets and liabilities by equating Macaulay duration of assets and Macaulay duration of liabilities. We could not reject the null hypothesis that there is no difference between average Macaulay duration of assets and that of liabilities. Our findings indicate that banks in Kuwait are able to match the durations of their assets and liabilities.
\end{abstract}

\section{Introduction}

Immunization of a bank portfolio may be defined as the protection of the nominal value of a portfolio against interest rate changes. In other words, a portfolio of investment is immunized for a holding period if its value at the end of the holding period, regardless of the course of interest rates during the holding period, must be at least as large as it would have been had the interest-rate function been constant throughout the holding period.

The risk inherent in the price fluctuations of a portfolio has many dimensions. These include default risk, inflation risk, and interest rate risk Baek, and Bandopadhyaya (1996), Ongena, and Smith (2001), Prisman, and Tian (1993), and Santarelli (2000). The most important single source of risk is basis-risk price fluctuations caused by shifts in interest rates. For a given shift in the yield curve, and holding other factors unchanged, longer term-to-maturity portfolio generally suffer greater price changes than shorter maturity portfolios.

One method of solving the interest rate risk problem is to adjust scheduled cash inflows and outflows such that they match each other in size at each prospective point in time. This "cash flow matching" technique solves the interest rate risk problem but imposes such severe constraints upon the decision maker that in most cases it is impractical if not impossible.

Alternative interest rate risk management techniques attempt to solve the problem by assuming certain restrictions on the permitted behavior of the term structure. These restrictions can be derived from theoretical models of the term structure, empirical observations, or simply by analytics. One of these techniques is duration, or for the purposes of this study traditional duration, is the weighted average time-to-maturity of a security's cash flows. The traditional duration measure is commonly and correctly criticized as providing a complete measure of risk only when interest rates experience identical, infinitesimal and instantaneous shifts. Chambers (1981) stated that refinements of the duration measure share similar criticisms because they are derived from hypothesized interest rate shifts and are, therefore, complete measures of risk only if actual interest rate shifts are identical to the hypothesized shifts. He goes on to say that duration refinements will continue to fail as long as researchers attempt to measure bond risk as a scalar.

Readers with comments or questions are encouraged to contact the authors via email. 
Chambers (1981) and Chambers and Carleton (1988) derive a vector of duration measures, and they claim that the elements of the vector used simultaneously permit near perfect interest rate risk control for virtually any interest rate shift including non-instantaneous and finite shifts. Chambers, Carleton, and Waldman (1984) demonstrate that the vector may be used to control the interest rate risk of financial futures positions.

This study analyzes immunization behavior of eight Kuwait banks during 1994 through 2000 period. In this endeavor, duration vectors of assets and duration vectors of liabilities are estimated. The results of this study suggest that the sample banks did immunize their portfolios of assets and liabilities by equating the Macaulay duration of assets to that of liabilities. The paper is organized as follows: section two reviews selected literature of duration strategies; data and methodology are presented in section three. Empirical findings are discussed in section four and the final section summarizes our findings.

\section{Review Of Literature}

Generally defined, immunization is protection of the nominal value of the portfolio against interest rate changes. The literature of interest rate risk can be divided into two time periods, before and after publication of the Fisher and Weil study in 1971. The time period before 1971 includes studies by Macaulay (1938), Hicks (1946), and others. After the 1971 time period, numerous studies refined the previous research and developed new techniques.

Fisher and Weil's (1971) study introduced immunization as an asset management strategy. In their study Fisher and Weil pointed out the problems involving misspecification of term structure of interest rates and its effect in achieving an immunized portfolio. Several portfolio strategies are presented in terms of standardized deviation of their wealth relative to the wealth attained under the assumption of zero reinvestment rate risk implying that a bond investment appreciates at the yield to maturity. The duration strategy was found more robust than the strategy of matching investment horizon. Macaulay duration measure, on the other hand, places a restriction on term structure of interest rates. That is to say, that the term structure changes only in height.

In a series of studies by Bierwag, Kaufman, Schweitzer, and Toevs (1981), and Gultekin and Rogalski (1985), it was reported that more elaborate duration measures do not outperform the simple Macaulay duration as far as achieving immunization objectives in the portfolio managers. The Macaulay duration was found to be preferred in light of its simplicity and lower implementation cost.

Chambers and Carleton (1988) fit a polynomial function to the term structure interest rates that is less restrictive than the functional form developed by Cooper (1977). Assuming that term structure of continuously compounded interest rates is a polynomial, Chambers and Carleton demonstrate that the finite and noninstantaneous return of a default free bond can be expressed as a vector and a shift vector. Chambers, Carleton and Waldman (1984) present empirical evidence that substantiates the claims that a polynomial may be used. Using the Taylor expansion series, Chambers and Carleton (1988) obtain vector durations to remedy the noninfinitesimal changes in the present value factors. Chambers, Carleton, and McEnally (1988) applied the vector duration model to default free portfolios and concluded that though the Macaulay duration provides enhanced immunization relative to maturity or naive approaches, the duration vector approach produces further improvements.

Benkato, Homaifar, and Haddad (1991), applied the Duration Vector Model and analyzed immunization behavior of a sample of large US banks during the 1967 through 1986 period. The financial market experienced both stable and volatile interest rates during this analysis period. They conclude that the sample banks seemed to immunize their portfolios by equating duration vector of assets and duration vector of liabilities.

Nawalkha and Chambers (1996), argue that current immunization models have limited power in interest rate protection. A new approach, entitled M-Absolute, is designed to provide powerful and practical single risk measure immunization in particular circumstances. Like duration, M-Absolute can be implemented as a simple, single risk measure immunization. 


\section{Data And Methodology}

\subsection{Data}

Data for eight Kuwait banks are included (see table 1). Each bank has complete data for the period 1994 through 2000. This small sample allows formation of the portfolio without compromising diversification. In addition, lending rates and annual treasury bill rates for Kuwait were collected from the International Monetary Funds, International Financial Statistics (2001). Annual lending rates were used to discount cash inflows for estimating duration vector of assets, while duration vector of liabilities is estimated by discounting the cash outflows using annual treasury bill rates ${ }^{1}$. Our choices are logical because cash inflows are more risky than outflows. In addition these two rates were used to estimate the parameters of the models presented later. Duration vectors are estimated by using Chambers and Carleton (1988) methodology.

\subsection{Methodology}

Because cash flows (inflows and outflows) are not readily available, we have to estimate them. The following part presents two models, one for estimating inflows and the other one for estimating outflows. The steps involved in developing these two regression models are as follow:

\begin{tabular}{cl|}
\hline & \multicolumn{1}{c|}{$\begin{array}{c}\text { Table 1 } \\
\end{array}$} \\
Sample Commercial Banks \\
\hline Bank No. & Bank Name \\
\hline 1. & AlAhli Bank of Kuwait \\
2. & Burgan Bank \\
3. & Bank of Kuwait and the Middle East \\
4. & Commercial Bank of Kuwait \\
5. & Gulf Bank \\
6. & Industrial Bank of Kuwait \\
7. & Kuwait Real Estate Bank \\
8. & National Bank of Kuwait \\
\hline
\end{tabular}

$$
\begin{aligned}
& \mathrm{COI}_{\mathrm{t}}=\mathrm{f}\left[\mathrm{r}_{\mathrm{t}}, \sigma_{\mathrm{t}}{ }^{2},\left(\mathrm{TA}_{\mathrm{t}}-\mathrm{TA}_{\mathrm{t}-1}\right)\right]+\mathrm{COI}_{\mathrm{t}}^{*} \\
& \text { Where: } \\
& \mathrm{COI}_{\mathrm{t}}=\text { total current operating income in period } \mathrm{t} \\
& \mathrm{r}_{\mathrm{t}}=\text { market interest rate in period } \mathrm{t}=\text { average } \\
& \text { annual yield on lending rate in period } t \\
& \sigma_{\mathrm{t}}^{2} \quad=\text { the variance of market interest rates in } \\
& \text { period } \mathrm{t} \\
& \text { TA } \quad=\text { total assets } \\
& \mathrm{f}=\text { functional operator } \\
& \mathrm{COI}_{t}{ }^{*}=\text { current operating income from old assets } \\
& \text { that have not matured by the end of period }
\end{aligned}
$$

The first component on the right hand side of equation 1 denotes current operating income from new assets and is assumed to be a function of $r_{t}$ (lending rate), and new assets $\left(\mathrm{TA}_{t}-\mathrm{TA} \mathrm{A}_{\mathrm{t}-1}\right)$. Based on Flannery (1981), this component can be approximated by:

$$
\mathrm{f}(*) \quad=\mathrm{r}_{\mathrm{t}}\left[\Omega\left(\mathrm{TA}_{\mathrm{t}}-\mathrm{TA}_{\mathrm{t}-1}\right)\right] \quad 0<\Omega<1
$$

where $\Omega$ denotes the average change in assets.

The second component of (1) is not affected by current market interest rates, and can be written as:

$$
\mathrm{COI}_{\mathrm{t}}^{*}=\mathrm{COI}_{\mathrm{t}-1}\left[1-\left(\mathrm{PTA}_{\mathrm{t}-1} / \mathrm{TA}_{\mathrm{t}-1}\right)\right]
$$

where:

PTA $_{t-1}=$ the dollar amount of assets $\left(\mathrm{TA}_{\mathrm{t}-1}\right)$, that matured at the end of period $\mathrm{t}-1$.

1 These are Kuwait rates and are obtained from the International Monetary Fund, International Financial Statistics, 2001. 
In (equation 3), the term [1 - $\left.\left(\mathrm{PTA}_{\mathrm{t}-1} / \mathrm{TA}_{\mathrm{t}-1}\right)\right]$ represents the ratio of old assets that have not matured to total old assets by the end of period t. Since this term is not observable, it is assumed that the term will remain constant through the years under study for each bank.

Let: $\mathrm{K}_{1}=1-\left(\mathrm{PTA}_{\mathrm{t}-1} / \mathrm{TA}_{\mathrm{t}-1}\right)$

Substituting (2), (3), and (4) into (1) and dividing through by $\left(\mathrm{TA}_{\mathrm{t}-1}\right)$ yields the following expression:

$$
\begin{aligned}
\mathrm{COI}_{\mathrm{t}} / \mathrm{TA}_{\mathrm{t}-1} & =\left\{\mathrm{r}_{\mathrm{t}}\left[\left(\mathrm{TA}_{\mathrm{t}}-\mathrm{TA}_{\mathrm{t}-1}\right) / \mathrm{TA}_{\mathrm{t}-1}\right]\right\}+\mathrm{K}_{1}\left(\mathrm{COI}_{\mathrm{t}-1} / \mathrm{TA}_{\mathrm{t}-1}\right) \\
\mathrm{COI}_{\mathrm{t}} / \mathrm{TA}_{\mathrm{t}-1} & =\left[\mathrm{r}_{\mathrm{t}}\left(\mathrm{TA}_{\mathrm{t}} / \mathrm{TA}_{\mathrm{t}-1}\right)\right]-\mathrm{r}_{\mathrm{t}}+\mathrm{K}_{1}\left(\mathrm{COI}_{\mathrm{t}-1} / \mathrm{TA}_{\mathrm{t}-1}\right)
\end{aligned}
$$

Allowing for the effect of some omitted explanatory variables, equation (6) can be rewritten as ${ }^{2}$ :

$$
\mathrm{COI}_{\mathrm{t}} / \mathrm{TA}_{\mathrm{t}-1}=\alpha_{0}+\alpha_{1}\left[\mathrm{r}_{\mathrm{t}}\left(\mathrm{TA}_{\mathrm{t}} / \mathrm{TA}_{\mathrm{t}-1}\right)\right]-\alpha_{2} \mathrm{r}_{\mathrm{t}}+\alpha_{3}\left[\left(\mathrm{COI}_{\mathrm{t}-1} / \mathrm{TA}_{\mathrm{t}-1}\right)\right]+\varepsilon_{\mathrm{t}}
$$

where:

$$
\begin{aligned}
& \varepsilon_{\mathrm{t}} \quad=\text { error term in period } \mathrm{t} . \\
& \alpha_{0}, \alpha_{1}, \alpha_{2} \text {, and } \alpha_{3} \text { are the regression coefficients. }
\end{aligned}
$$

Other variables as defined above.

Relationship (7) is the regression equation used to estimate the regression coefficients in the case of assets. The value of $K_{1}$ is measured by $\alpha_{3}$ coefficient, and it must be between 0 and 1 .

Similarly, total current operating expenses (COE) are a function of total liabilities (TL) and of the ratio of old liabilities that have not matured by the end of period $t-1$ to old liabilities $\left(\mathrm{K}_{2}\right)$. In addition, $(\mathrm{COE})$ is a function of $\mathrm{r}_{\mathrm{t}}$ (treasury bill rate). This relationship can be shown (similar to the derivation of equation 7) as:

$$
\mathrm{COE}_{\mathrm{t}} / \mathrm{TL}_{\mathrm{t}-1}=\beta_{0}+\beta_{1}\left[\mathrm{r}_{\mathrm{t}}\left(\mathrm{TL}_{\mathrm{t}} / \mathrm{TL}_{\mathrm{t}-1}\right)\right]-\beta_{2} \mathrm{r}_{\mathrm{t}}+\beta_{3}\left[\left(\mathrm{COE}_{\mathrm{t}-1} / \mathrm{TL}_{\mathrm{t}-1}\right)\right]+\mu_{\mathrm{t}}
$$

where:

$$
\begin{array}{ll}
\mathrm{TL} & =\text { total liabilities } \\
\mu_{\mathrm{t}} & =\text { error term in period } \mathrm{t}
\end{array}
$$

$\beta_{0}, \beta_{1}, \beta_{2}$, and $\beta_{3}$ are the regression coefficients.

Other variables as defined above.

Relationship (8) is the regression equation used to estimate the regression coefficients in the case of liabilities. The ratio of total old liabilities that have not matured to old liabilities at the beginning of the period $\left(\mathrm{K}_{2}\right)$ is measured by $\beta_{3}$ coefficient, and it must be between 0 and 1 .

We then applied Zellner's (1962) technique ${ }^{3}$ for seemingly unrelated regression to estimate equations (7) and (8) coefficients (results may be obtained from the authors). The reciprocal of $\left(1-\alpha_{3}\right.$ i.e. $\left.1-\mathrm{K}_{1}\right)$ and the reciprocal of $\left(1-\beta_{3}\right.$ i.e. $1-\mathrm{K}_{2}$ ) represent the amortization period (in years) of total assets and total liabilities, respectively. To avoid double counting, only the change in total assets (total liabilities) is taken into account. For example, if $\alpha_{3}$ is 0.60 , the reciprocal of $\left(1-\alpha_{3}\right)$ is 2.5 years representing years to maturity of that asset.

2 Equation (7) is the regression equation that could be used to estimate the value of $\mathrm{K}_{1}$ for each bank. However, if the bank faces income taxes, $\mathrm{COI}$ needs to be adjusted for any tax exempt income items, otherwise COI is not directly comparable with current operating expenses (COE). Equation (7) must therefore be converted to a tax equivalent basis. Because Kuwait has no income tax, equation (7) is appropriate. The term $\sigma_{t}^{2}$ is not shown in equations 6 nor 7 because it was found to be insignificant.

3 Zellner's technique was used to take into account the high probability that some explanatory variables were omitted from the regression equations; that there may be non-zero correlation between the disturbance terms; and, finally, asymptotically, Zellner's technique will result in more efficient estimates than those obtained by the application of ordinary least squares. 


\subsection{Estimating Cash Flows}

Once we estimated maturities, then we estimated cash flows from following two sources:

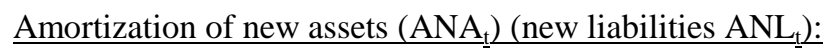

The annual amortization of new assets (new liabilities) is estimated by dividing the change in new assets (new liabilities) by estimated year's to maturity (T). For example, if $\mathrm{T}$ is 2.5 years and new assets at the beginning of year $\mathrm{t}$ is KD100.00, the first KD 40.00 will be amortized at the beginning of year $t+1$. The second KD 40.00 will be amortized at the beginning of year $\mathrm{t}+2$ and the remaining KD 20.00 will be amortized at the beginning of year $\mathrm{t}+3$.

\section{Income (expenses) from new assets (liabilities):}

Income from change in total assets at the end of each period $\left(\mathrm{COIN}_{\mathrm{t}}\right)$ is calculated as follows:

$$
\begin{array}{ll}
\operatorname{COIN}_{t+1} & =\operatorname{COI}_{\mathrm{t}}-\left(\alpha_{3}\right) *\left(\mathrm{COI}_{\mathrm{t}-1}\right) \\
\operatorname{COIN}_{\mathrm{t}+2,3} & =\operatorname{COIN}_{\mathrm{t}+1} *\left[1-\left(1-\alpha_{3}\right) * \mathrm{~m}\right]
\end{array}
$$

Equation (10) is derived from equations (1), (3) and (9), weighted by the percentage of the remaining years of that new asset $\left[1-\left(1-\alpha_{3}\right) \mathrm{m}\right]$, where $\mathrm{m}$ is the cumulative number of years that the assets been in use (i.e., $\mathrm{m}=0,1,2, \ldots \mathrm{T})$. For example, if $\mathrm{COI}_{\mathrm{t}}=\mathrm{KD} 200, \mathrm{COI}_{\mathrm{t}-1}=\mathrm{KD} 150, \alpha_{3}=0.60$, and $\mathrm{T}=2.5$ years. Then:

$$
\begin{aligned}
& \mathrm{COIN}_{\mathrm{t}+1}=[200-(0.60)(150)] *[1-(1-0.60) *(0)]=\mathrm{KD} 110 \\
& \mathrm{COIN}_{\mathrm{t}+2}=(110) *[1-(1-0.60) *(1)]=\mathrm{KD} 66 \\
& \mathrm{COIN}_{\mathrm{t}+3}=(110) *[1-(1-0.60) *(2)] \quad=\mathrm{KD} 22
\end{aligned}
$$

Similarly, expenses of change in total liabilities $\left(\mathrm{COEN}_{t}\right)$ are:

$$
\begin{array}{ll}
\mathrm{COEN}_{\mathrm{t}+1} & =\mathrm{COE}_{\mathrm{t}}-\left(\beta_{3}\right) *\left(\mathrm{COE}_{\mathrm{t}-1}\right) \\
\mathrm{COEN}_{\mathrm{t}+2,3, \ldots} & =\mathrm{COEN}_{\mathrm{t}+1} *\left[1-\left(1-\beta_{3}\right) * \mathrm{~m}\right]
\end{array}
$$

Once cash inflow (outflow) was estimated, we calculated duration vector of assets $\left(\mathrm{DAn}_{\mathrm{jt}}\right)$, and of liabilities $\left(\mathrm{DLn}_{\mathrm{jt}}\right)$ for each bank for each year. According to Chambers (1981), Chambers, and Carleton (1988), Chambers, Carleton, and Waldman (1984), and Chambers, Carleton, and McEnally (1988), the duration vector approach permits near perfect interest rate risk control for virtually any interest rate shift including noninstaneous and finite shifts. Macaulay`s duration is appropriate if interest rates experience instantaneous, infintesimal and identical shifts. As a result, Macaulay`s duration may fail to provide perfect protection from random behavior of interest rates. Duration vectors are calculated for the sample banks as follows:

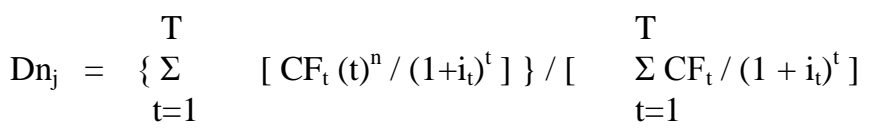

where:

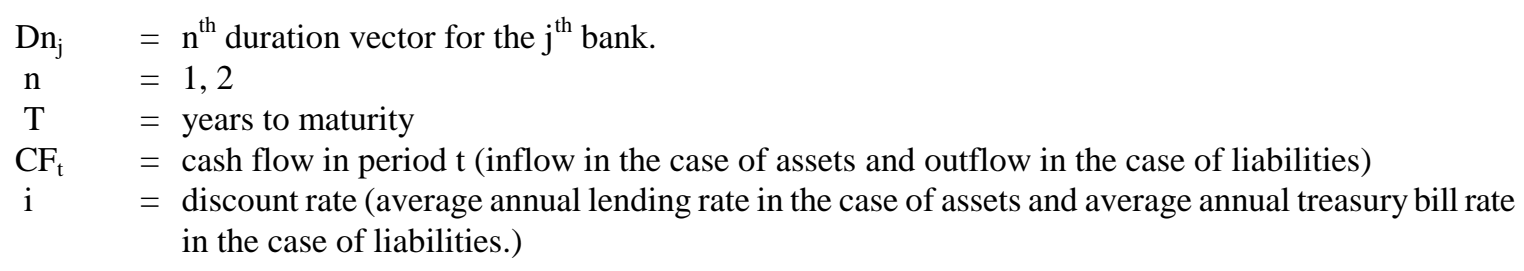


Then, for each bank $\mathrm{j}$, we calculated the average duration vector ( of the annual durations ) of assets $\left(\mathrm{DAn}_{\mathrm{j}}\right.$ ) and liabilities $\left(\mathrm{DLn}_{\mathrm{j}}\right)$ by solving for the arithmetic mean of the annual durations vectors. Finally, the average duration vector of assets (DAn) and the average duration vector of liabilities (DLn) for all banks are calculated by solving for the arithmetic averages of $\mathrm{DAn}_{\mathrm{j}} \mathrm{s}$ and $\mathrm{DLn}_{\mathrm{j}} \mathrm{s}$ respectively.

\subsection{Empirical Results}

Table 2 reports the average duration vectors of assets (liabilities) for each bank in the sample. Two vectors of duration were estimated, DA1 and DA2 for assets and two vectors of durations DL1 and DL2 for liabilities. Macaulay duration is equal to DA1 for assets (DL1 for liabilities), while DA2 is for assets (DL2 for liabilities) approximates convexity in the term structure of interest rates. The estimated overall average values of DA1 (DAn1) was found to be 3.568, and that of DL1 (DLn1)was 4.387 years. Meanwhile, the average bank portfolio durations for assets and liabilities of DA2 (DAn2) and of DL2 (DLn2) are estimated to be equal to 16.085 and 26.626 years respectively.

A small sample test of differences is conducted with the following two hypotheses:

$$
\begin{array}{lll}
\text { 1. } & \text { Ho: } & \text { DAn1(assets) } \\
\text { Ha: } & \text { Reject Ho } & \\
\text { 2. } & \text { Ho: } & \text { DAn2(assets) } \\
\text { Ha: } & \text { Reject Ho }
\end{array}
$$

The estimates of the two tail t-test statistics for the above two hypotheses are -1.2926, and 1.8127, respectively, while the t-statistics at 5 percent level of significance (two- tailed test for this sample size) is 1.706 . Therefore, we cannot reject the null hypothesis that there is no difference between average duration of assets (DAn1) and average duration of liabilities (DLn1). However; average duration of assets (DAn2) being equal to average duration of liabilities (DLn2) is rejected. This means that on average the sample eight Kuwait banks did not accomplish an immunization resulting from noninfinitesimal changes in interest rates. The selected banks for this study seem to have adjusted their portfolio of

\begin{tabular}{|c|c|c|c|c|}
\hline \multirow[t]{2}{*}{ BANK \# } & \multicolumn{4}{|c|}{ DURATIONS } \\
\hline & $\begin{array}{c}\text { ASSETS } \\
\text { DA1 }\end{array}$ & $\begin{array}{c}\text { LIABILITIES } \\
\text { DL1 } \\
\end{array}$ & $\begin{array}{c}\text { ASSETS } \\
\text { DA2 }\end{array}$ & $\begin{array}{c}\text { LIABILITIES } \\
\text { DL2 }\end{array}$ \\
\hline 1 & 4.637 & 5.235 & 23.785 & 35.590 \\
\hline 2 & $3.021 *$ & 4.248 & 12.141 & 25.158 \\
\hline 3 & $4.296^{*}$ & 4.791 & 21.334 & 30.896 \\
\hline 4 & $4.987 *$ & 4.619 & 26.309 & 29.074 \\
\hline 5 & 3.029 & 4.328 & 12.201 & 26.006 \\
\hline 6 & 3.038 & 4.041 & 12.263 & 22.965 \\
\hline 7 & 2.820 & 3.946 & 10.696 & 21.970 \\
\hline 8 & 2.717 & 3.887 & 9.954 & 21.347 \\
\hline \multicolumn{5}{|c|}{ OverallAverage for All Banks } \\
\hline & DAn1 & DLn1 & DAn2 & DLn2 \\
\hline & 3.568 & 4.387 & 16.085 & 26.626 \\
\hline \multicolumn{5}{|c|}{ Standard Deviation } \\
\hline & 0.834 & 0.218 & 43.320 & 24.297 \\
\hline
\end{tabular}
assets (liabilities) in achieving desired durations for hedging against changes in market interest rates.

Table 2

Durations Vector in Years of Assets and Liabilities of the Sample Banks

*Banks with longer duration vector maturities of assets than liabilities. 


\section{Summary And Conclusion}

This study analyzed the portfolio behavior of eight Kuwait selected banks during the period of 1994 through 2000. The financial market in Kuwait experienced relative stability of interest rates during the analysis period. The sample banks seemed to adjust their portfolio of assets and liabilities by equating Macaulay duration of assets and Macaulay duration of liabilities. We could not reject the null hypothesis that there is no difference between average Macaulay duration of assets and that of liabilities. Our findings indicate that banks in Kuwait are able to match the durations of their assets and liabilities. However, on average the sample eight Kuwait banks did not accomplish an immunization resulting from noninfinitesimal changes in interest rates. With a word of caution, we could argue that the sample banks had taken steps to immunize their portfolios of assets (liabilities) against rises in interest rates.

We do realize that neither the sample size nor the years of data are large enough. Future research should not only include more banks and more years of data but should include other countries in the Middle East and North Africa. This project is in progress.

\section{References}

1 Baek, In-Mee and Arindam Bandopadhyaya. "The Determinants of the Duration of Commercial Bank Debt Renegotiation for Sovereigns", Journal of Banking and Finance, 1996, v20 (4, May), 673-685.

2 Benkato, Omar M., Ghassem Homaifar, and Mahmoud M. Haddad, "Interest Rate Risk Immunization Using Duration Vector Approach for Commercial Banks". Journal of Financial \& Strategic Decisions, (Winter 1991), 85-97.

3 Bierwag, G. O.: G. C. Kaufman, R. Schweitzer, and A. Toevs. "The Art of Risk Management in Bond Portfolios". Journal of Portfolio Management, 7 (Spring 1981), 27-36.

4 Chambers, D. R., "The Management of Default-free Bond Portfolio", Unpublished Ph.D. dissertation, The University Of North Carolina at Chapel Hill (1981).

5 Chambers, D. R., and W. T. Carleton, "Generalized Approach to Duration". Research in Finance, 1988, v7, 163-182.

6 Chambers, D. R., W. T. Carleton and D. M. Waldman, "Estimation of the Term Structure of Interest Rates Using a Simple Polynomial”, Journal of Financial and Quantitative Analysis, 19 (Sept. 1984), 233-252.

7 Chambers, D. R., W. T. Carleton and R. W. McEnally, "Immunizing Default-free Bond Portfolios With A Duration Vector", Journal of Financial and Quantitative Analysis, 23 (March, 1988), 89-104.

8 Cooper, I. A., "Asset Values, Interest Rate Changes, and Duration”. Journal of Financial and Qualitative Analysis (December 1977), 701-723.

9 Fisher, L., and R. L. Weil, "Coping With the Risk of Interest Rate Fluctuations: Returns to Bondholders from Naive and Optimal Strategies", Journal of Business, 44 (October, 1971), 408-431.

10 Flannery, M. J. "Market Interest Rates and Commercial Bank Profitability: An Empirical Investigation", Journal of Finance, Vol. 36, No. 5 (December, 1981), pp. 1085-1101.

11 Gultekin, G. R., and R. J. Ragalski, "Alternative Duration Specifications and the Measurement of Basic Risk: Empirical Tests", Journal of Business, 57 (October, 1985), 241-264.

12 Hicks, J. R. Value and Capital, Oxford University Press (1946).

13 International Monetary Fund, International Financial Statistics, 2001.

14 Macaulay, F. R., "Some Theoretical Problems Suggested by the Movements of Interest Rates, Bond Yields and Stock Prices in the U.S. Since 1856", New York: National Bureau of Economic Research (1938).

15 Nawalkha, Sanjay K., and Donald R. Chambers, "An Improved Immunization Strategy: M-Absolute", Financial Analysts Journal, (September/October 1996), pp. 69-76.

16 Ongena, Steven and David C. Smith. "The Duration of Bank Relationships", Journal of Financial Economics, 2001, v61 (3, Sep), 449-475.

17 Prisman, E. Z. and Y. Tian. "Duration Measures, Immunization, And Utility Maximization", Journal of Banking and Finance, 1993, v17 (4), 689-707.

18 Santarelli, E. “The Duration of New Firms in Banking: An Application of Cox Regression Analysis", Empirical Economics, 2000, v25 (2), 315-326.

19 Zellner, A. "An Efficient Method of Estimating Seemingly Unrelated Regressions and Tests for Aggregation Bias". Journal of American Statistical Association, Vol. 57 (1962), pp. 348-368. 
Notes 